\title{
Ankle dexterity is less impaired than muscle strength in incomplete spinal cord lesion
}

\section{Journal Article}

\section{Author(s):}

Wirth, B.; van Hedel, Hubertus J.A.; Curt, A

Publication date:

2008

Permanent link:

https://doi.org/10.3929/ethz-b-000013622

\section{Rights / license:}

In Copyright - Non-Commercial Use Permitted

\section{Originally published in:}

Journal of neurology 255(2), https://doi.org/10.1007/s00415-008-0724-y 


\author{
Brigitte Wirth \\ Hubertus J.A.van Hedel \\ Armin Curt
}

\section{Ankle dexterity is less impaired than muscle strength in incomplete spinal cord lesion}

Received: 21 April 2007

Received in revised form: 21 July 2007

Accepted: 21 August 2007

Published online: 22 January 2008
B. Wirth $(\varangle) \cdot$ H. J. A. van Hedel

Spinal Cord Injury Center

Balgrist University Hospital

Forchstrasse 340

8008 Zurich, Switzerland

Tel.: +41-44/386-3729

Fax: +41-44/386-3731

E-Mail: bwirth@paralab.balgrist.ch

B. Wirth

Institute of Human Movement Sciences and Sport

Swiss Federal Institute of Technology

8092 Zurich, Switzerland

A. Curt

ICORD and Division of Neurology

University of British Columbia

2469-6270 University Blvd

Vancouver, BC V6T 1Z4, Canada
Abstract Background Motor assessment after incomplete spinal cord injury (iSCI) currently consists of tests for muscle strength (manual muscle testing) and gait. The ability to adequately time a movement, an aspect of dexterity, is not tested. Thus, this study assessed the timing of ankle dorsiflexion in iSCI patients in the supine position and during gait and examined its relation to measures for muscle strength, corticospinal conductivity and gait speed. Methods In 12 subjects with iSCI and 12 matched controls, timing of ankle dorsiflexion was tested by means of auditory-paced dorsiand plantar-flexion movements at three frequencies in the supine position and by determining initiation and termination of dorsiflexion in swing during gait. In addition, maximal movement velocity (MMV) in the ankle task, maximal voluntary contraction (MVC), corticospinal conductivity (motor evoked potentials (MEP)) and gait speed (10 Meter Walk Test) were assessed. Results The groups did not significantly differ in timing of ankle dorsiflexion, neither in the supine position nor in gait. However, they significantly differed in MMV at all frequencies, MEP latency, MEP amplitude and gait speed. In contrast to ankle timing in the supine position, the onset of dorsiflexion in swing during gait significantly correlated to the dynamic MEP parameters. Conclusions Although MMV and gait speed were significantly reduced, timing of ankle dorsiflexion, both in the supine position and during gait, was less impaired in iSCI patients. This indicates that the loss of strength, particularly of dynamic strength, is the major motor impairment in iSCI, which might be considered when assessing treatment interventions.

Key words dexterity. incomplete spinal cord injury . motor evoked potential $\cdot$ muscle strength

\section{Introduction}

Patients with an incomplete spinal cord injury (iSCI) often show considerable motor recovery [37] and the majority of patients who initially had some preserved motor function below the level of lesion become pedestrians (about $90 \%$ in traumatic SCI) [19]. The clin- ical assessment of motor deficits after iSCI currently consists of a measurement for muscle strength (manual muscle testing according to the American Spinal Injury Association (ASIA) [2]), gait tests $[16,17,33,34]$ and an assessment of independence in activities of daily living [9].

Muscle strength, however, is only one component of motor function that can be impaired after a lesion of the 
central nervous system (CNS). In upper limb studies with stroke patients, dexterity, defined as adroitness and competency in use of the limbs [7], was shown to be a separate aspect of motor control, which is not restricted to manual tasks $[1,8]$. In iSCI, a recent study showed that dexterity in the supine position, defined as the adequate timing of ankle dorsi- and plantar-flexion movements, was only slightly affected, while muscle strength was substantially reduced [38].

In the assessment of gait in iSCI patients, only gait speed and the usage of walking aids are currently being assessed $[16,17,33,34]$, while studies focusing on kinematic gait characteristics in iSCI patients have been rare [27]. Nevertheless, the swing phase of gait is particularly susceptible to corticospinal influence on the motoneuron pool $[31,32]$. Thus, the control of ankle dorsiflexion during swing might be altered in iSCI patients, which could lead to impaired walking ability and enhanced risk for falls [26].

For these reasons, the aims of this study were to compare timing of ankle dorsiflexion as an aspect of dexterity in both the swing phase during gait and in the supine position between iSCI patients and control subjects and to relate it to corticospinal conductivity (motor evoked potentials (MEP) $[12,14,36])$ and to measures for muscle strength and gait speed.

\section{Methods}

\section{Subjects}

All procedures were in accordance with the standards of the local ethics committee and with the Declaration of Helsinki. All subjects gave informed written consent to participate in the study. The $12 \mathrm{pa}-$ tients with iSCI ( 9 males; age $=58.3$ years \pm standard deviation 10.7 years) were recruited from the Spinal Cord Injury Center, Balgrist, Zurich, Switzerland. All of them had preserved motor function below the neurological level (ASIA C or D) and the spinal lesion occurred on average 2.65 years ( \pm 3.53 years) ago, ranging from 1 to 117 months (Table 1). The elderly control subjects (matched for gender and age $=59.2$ years \pm 11.3 years) were recruited via the local university department for senior citizens. Data of the more affected limb of the iSCI patients were compared to those of the weaker limb of the controls, which was defined by the muscle strength of the dorsiflexor muscles, since these muscles were the focus of this study.

\section{Experimental procedure}

\section{Assessments during gait}

\section{Timing of ankle dorsiflexion in swing}

The subjects walked on a treadmill at $2.5 \mathrm{~km} / \mathrm{h}$. All patients (and the control subjects on request) wore a safety harness that was attached to the ceiling and all partici-

Table 1 Characteristics of the iSCl patients

\begin{tabular}{|c|c|c|c|c|c|c|c|c|c|}
\hline $\begin{array}{l}\text { Age } \\
\text { (years) }\end{array}$ & Cause of lesion & $\begin{array}{l}\text { Level of } \\
\text { lesion }\end{array}$ & $\begin{array}{l}\text { ASIA } \\
\text { category }\end{array}$ & $\begin{array}{l}\text { Time } \\
\text { interval } \\
\text { since SCl } \\
\text { (months) }\end{array}$ & $\begin{array}{l}\text { ASIA motor } \\
\text { score } \\
\text { dorsiflexor } \\
\text { muscles }\end{array}$ & $\begin{array}{l}\text { ASIA motor } \\
\text { score } \\
\text { plantarflexor } \\
\text { muscles }\end{array}$ & WISCIII & $\begin{array}{l}\text { Maximal } \\
\text { gait speed } \\
(\mathrm{m} / \mathrm{s})\end{array}$ & $\begin{array}{l}\text { Preferred } \\
\text { gait speed } \\
(\mathrm{m} / \mathrm{s})\end{array}$ \\
\hline 37 & Epidural haematoma & T6 & D & 1 & 3 & 4 & 16 & 0.69 & 0.50 \\
\hline 44 & Stenosis & $\mathrm{C} 5$ & D & 15 & 5 & 5 & 20 & 1.83 & 1.44 \\
\hline 53 & Trauma & C3 & D & 117 & 5 & 5 & 20 & 2.19 & 1.44 \\
\hline 53 & Trauma & $\mathrm{T} 10$ & D & 112 & 5 & 5 & 20 & 1.14 & 1.00 \\
\hline 57 & Epidural phlegmon & T11 & D & 7 & 4 & 4 & 19 & 0.94 & 0.69 \\
\hline 59 & Meningeom & T9 & C & 5 & 3 & 4 & 16 & 0.97 & 0.92 \\
\hline 60 & Intramedullar ependymom & $\mathrm{T} 12$ & D & 1 & 4 & 4 & 16 & 1.00 & 0.67 \\
\hline 61 & Intramedullar neurinom & $C 2$ & D & 57 & 5 & 4 & 20 & 1.83 & 1.00 \\
\hline 63 & Trauma & C5 & $\mathrm{C}$ & 49 & 3 & 4 & 16 & 0.86 & 0.78 \\
\hline 66 & Trauma & C6 & $\mathrm{D}$ & 22 & 5 & 5 & 20 & 2.08 & 1.14 \\
\hline 70 & Ischemia & $\mathrm{T} 7$ & D & 1 & 4 & 4 & 16 & 0.86 & 0.53 \\
\hline 76 & Trauma & C4 & $D$ & 3 & 5 & 4 & 20 & 1.53 & 1.19 \\
\hline
\end{tabular}

Level of lesion: C cervical; $T$ thoracic; ASIA American Spinal Injury Association

ASIA motor score:

3 active movement, full range of motion against gravity; 4 active movement, full range of motion against moderate resistance; 5 active movement, full range of motion against full resistance

ASIA category:

C more than half of the key muscles have a muscle grade less than $3 ; D$ at least half of the key muscles have a muscle grade greater than or equal to 3

WISCI II: Walking index for Spinal Cord Injury II:

16 Ambulates with two crutches, no braces and no physical assistance, 10 meters; 19 Ambulates with one cane/crutch, no braces and no physical assistance, 10 meters; 20 Ambulates with no devices, no braces and no physical assistance, 10 meters 
pants were instructed to hold the hand railings that were parallel to the treadmill. Four force sensors underneath the treadmill recorded the phases of gait cycle, two electrogoniometers (Biometrics Ltd, Gwent, UK) the ankle movements. All subjects underwent a period of familiarization with treadmill walking under test conditions and subsequently, 20 consecutive complete step cycles (in order to avoid alterations of gait parameters due to fatigue) were collected for analysis. For analysis, the raw data were cut into single steps at the beginning of stance phase, averaged and normalized to 1000 samples. Initiation of dorsiflexion was determined by the time of the minimum in the ankle goniometer curve at the beginning of the swing phase [26], termination of dorsiflexion in swing by the maximum of the goniometer curve during swing. All data were analyzed using SOLEASY software (ALEA solutions $\mathrm{GmbH}$, Zurich Switzerland) and Matlab 6.5 (The MathWorks, Natick, Massachusetts, United States).

\section{Gait speed}

Gait speed was assessed by a 10 Meter Walk Test $[33,34]$. The subjects walked on a flat stretch of about 14 meters length at their preferred and maximal gait speed. The time taken to walk the 10 meter distance in the middle (to avoid effects of acceleration and deceleration) were manually measured by means of a stopwatch. Gait speed data were normalized by dividing speed by body height $\left[\mathrm{s}^{-1}\right]$.

\section{Assessments in the supine position}

\section{Timing of ankle dorsiflexion}

A detailed description of the test protocol was published previously [38]. In short, computer-generated tones were presented to the subjects in blocks of different frequencies $(0.8,1.6$ and $2.4 \mathrm{~Hz})$. The subjects (in the supine position) were instructed to follow the tones (1) with their foot as accurately to the tones as possible and (2) with the largest range of motion (ROM) possible. For each frequency, the subjects had to perform 20 dorsiand plantar-flexion repetitions. They were able to visually control foot movements to compensate for impaired proprioception, but this was not explicitly instructed. Data from the first 5 movement cycles were not included in the analysis, since a minimum of 3 to 5 signals are required for picking up the beat [3]. From the remaining 15 ankle dorsiflexions and 15 plantarflexions, accuracy of timing was determined for each frequency by averaging the duration of movement cycles, converting the result to frequency and comparing it to the target frequency [38].

\section{Maximal movement velocity and muscle strength}

Maximal movement velocity (MMV) in dorsiflexion was calculated by deriving the goniometer data and then averaging the maximal movement speed per cycle. Maximal voluntary contraction (MVC) was measured using a custom-built torque measuring device that prevented any movement at the ankle and any influence of the weight of the lower limb on the torque measurement [14]. The subjects were asked to pull their foot as forcefully as possible. The measurement was taken when they had been holding the torque constant for about two seconds. Finally, the torque data were normalized by dividing torque by body weight $[\mathrm{Nm} / \mathrm{kg}][24]$.

\section{Transcranial magnetic stimulation}

Transcranial magnetic stimulation (TMS) and EMG measurement were performed analogous to previous studies [14,36]. Single pulses of $200 \mu$ s were delivered by means of a magnetic stimulator (MagPro, Denmark). For all measurements, a figure eight-shaped coil was used. Individual coil position and stimulation threshold were determined at the beginning of the recording. Threshold intensity was defined as the percentage of stimulator output that evoked a MEP amplitude of at least $50 \mu \mathrm{V}$ in approximately $50 \%$ of 10 consecutive stimuli [36]. Stimulation intensity was set at $1.2 \mathrm{x}$ threshold intensity. TMS was performed in all patients at $20 \%$ MVC [14] using the above described torque measuring device, while visual feedback about the contraction level was provided. Excitability and facilitation of MEP was studied during a static and a dynamic contraction condition of the tibialis anterior muscle (TA). The average of five measurements per condition was analysed [14, 36].

The EMG electrodes were placed on the middle of the TA muscle belly (inter-electrode distance $2 \mathrm{~cm}$ ). The level of background muscle activity was calculated by the root mean square (RMS) of TA during $200 \mathrm{~ms}$ before the stimulus [14]. MEP amplitude was determined by calculating the RMS over a time window of $20 \mathrm{~ms}$ from the onset of the MEP and by subtracting background activity from the total MEP. MEP latency was defined as the time between TMS trigger and the MEP response using the cumulative sum method, which allows for a reliable determination of MEP latency and amplitude. Lastly, the MEP latency values were normalized by dividing MEP latency by body height $[\mathrm{ms} / \mathrm{m}][36]$.

\section{Statistical analysis}

With a view to the small sample size of the groups, differences in performance between the groups were ana- 
lyzed using the non-parametric Wilcoxon rank sum tests. Spearman correlation was used to examine correlations between the parameters. The significance level $\alpha$ was set at 0.05 for all tests.

\section{Results}

\section{Group differences in timing of ankle dorsiflexion}

The groups did not significantly differ in the timing of ankle dorsiflexion, neither in gait (Fig. 1A) nor in the supine position (Fig. 1B). While walking, the iSCI patients initiated dorsiflexion during swing on average at $67 \%$ ( \pm standard deviation $1.4 \%$ ) and terminated it at $83.3 \%( \pm 3.3 \%)$ of the gait cycle. The swing phase in the control group started on average at $66.5 \%( \pm 1.4 \%)$ and finished at $87.5 \%( \pm 8.8 \%)$ of the gait cycle. In the supine position, the deviation between performance and target frequency was larger in the iSCI group than in the control group at all frequencies, but the differences between the groups were not significant (deviation from target frequency in the iSCI group: $0.8 \mathrm{~Hz}$ : average $=0.009 \mathrm{~Hz}( \pm 0.015 \mathrm{~Hz}) ; 1.6 \mathrm{~Hz}$ : average $=0.067 \mathrm{~Hz}$ $( \pm 0.127 \mathrm{~Hz}) ; 2.4 \mathrm{~Hz}$ : average $=0.280 \mathrm{~Hz}( \pm 0.358 \mathrm{~Hz})$; deviation from target frequency in the control group: 0.8 $\mathrm{Hz}$ : average $=0.004 \mathrm{~Hz}( \pm 0.003 \mathrm{~Hz}) ; 1.6 \mathrm{~Hz}$ : average $=0.026( \pm 0.040 \mathrm{~Hz}) ; 2.4 \mathrm{~Hz}$ : average $=0.142 \mathrm{~Hz}$ $( \pm 0.157 \mathrm{~Hz})$. Timing of ankle movements in the supine position at all frequencies and initiation or termination of dorsiflexion in swing did not correlate.

\section{Timing of ankle dorsiflexion versus MEP}

Static MEP amplitude was $0.065 \mathrm{mV}( \pm 0.046 \mathrm{mV})$ in the iSCI group and $0.195 \mathrm{mV}( \pm 0.176 \mathrm{mV})$ in the control group. Static MEP latency was $23.05 \mathrm{~ms} / \mathrm{m}( \pm 4.3 \mathrm{~ms} / \mathrm{m})$ in the iSCI group and $20.33 \mathrm{~ms} / \mathrm{m}( \pm 1.6 \mathrm{~ms} / \mathrm{m})$ in the control group. In the dynamic condition, the MEP amplitude was $0.089 \mathrm{mV}( \pm 0.040 \mathrm{mV})$ in the iSCI group and $0.226 \mathrm{mV}( \pm 0.173 \mathrm{mV})$ in the control group. Dynamic MEP latency was $23.64 \mathrm{~ms} / \mathrm{m}( \pm 5.0 \mathrm{~ms} / \mathrm{m})$ in the iSCI group and $18.99 \mathrm{~ms} / \mathrm{m}( \pm 2.0 \mathrm{~ms} / \mathrm{m})$ in the control group. The groups significantly differed in static $(p=0.006)$ and dynamic $(\mathrm{p}=0.006)$ MEP amplitude as well as in static $(p=0.050)$ and dynamic $(p=0.019)$ MEP latency. In the iSCI group, the time of dorsiflexion initiation in swing correlated significantly to static and dynamic MEP latency (Spearman correlation coefficient $r_{S}=0.79$ $(\mathrm{p}=0.006)$ and $\mathrm{r}_{\mathrm{S}}=0.68(\mathrm{p}=0.02)$, respectively). With a view to the supine position, the MEP parameters did not correlate to the deviation from target frequency.
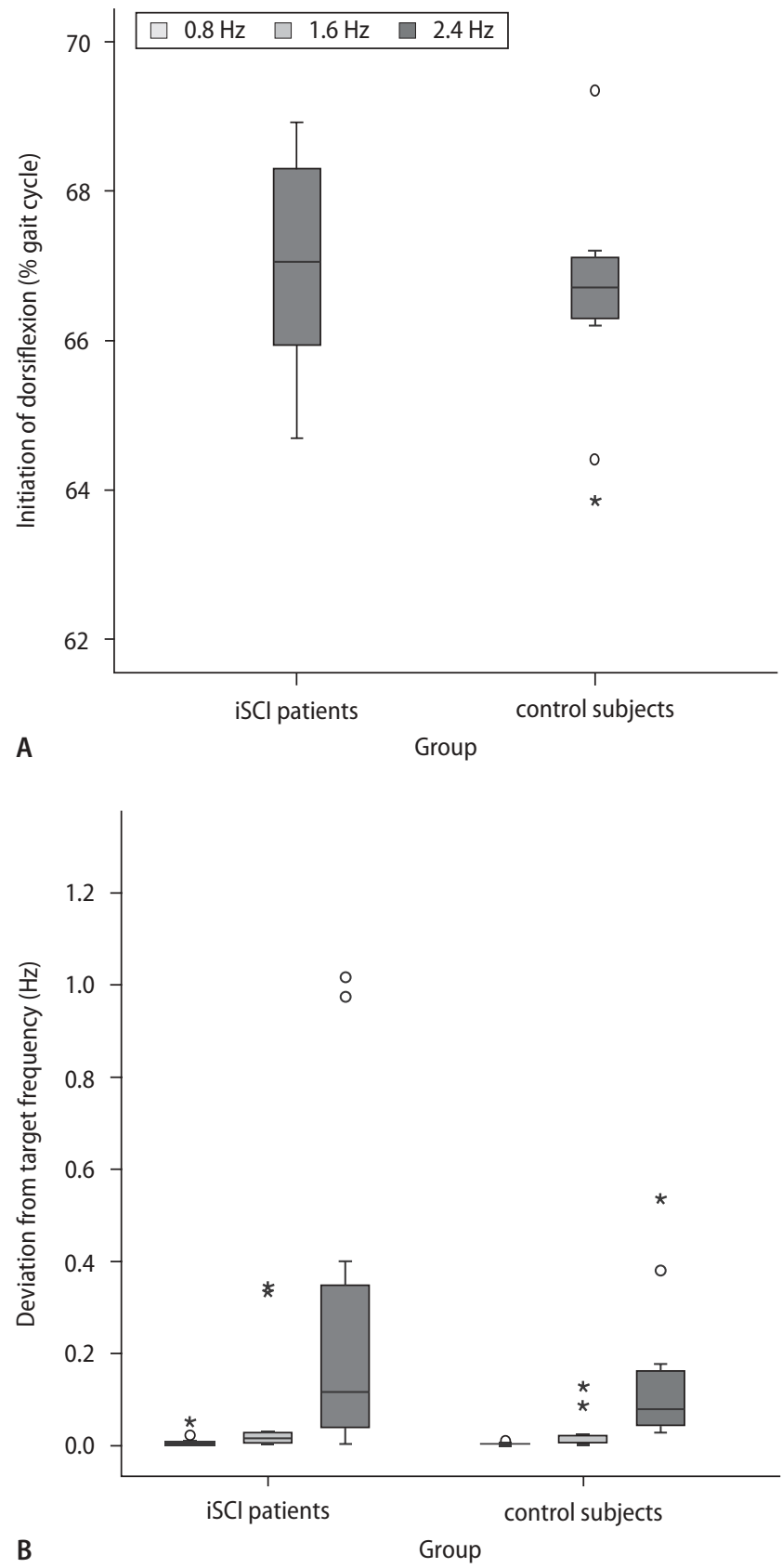

Fig. 1 Timing of ankle dorsiflexion. The timing of ankle dorsiflexion in the swing phase of gait (A) and in the supine position (B), as assessed at three different frequencies $(0.8,1.6,2.4 \mathrm{~Hz})$ of audio-paced movements, is not significantly reduced in the iSCl group. Circles in the boxplot indicate outlier values that are between the 1.5 and 3 interquartile range from the end of the box. Stars indicate extreme values that are more than 3 times the interquartile range from the end of the box.

\section{Timing of ankle dorsiflexion versus MMV and MVC}

MMV in the foot task was significantly higher in the control group at all frequencies $(0.8 \mathrm{~Hz}$ : $\mathrm{p}=0.002 ; 1.6 \mathrm{~Hz}$ : $\mathrm{p}=0.001 ; 2.4 \mathrm{~Hz}: \mathrm{p}=0.028)($ Fig. $2 \mathrm{~A})$. At $0.8 \mathrm{~Hz}, \mathrm{MMV}$ in dorsiflexion was $145.9 \% \mathrm{~s}( \pm 50.0 \%$ s $)$ in the iSCI group 
and $222.4 \% \mathrm{~s}( \pm 57.2 \% \mathrm{~s})$ in the control group. At $1.6 \mathrm{~Hz}$, MMV of the iSCI patients and the controls was on average $176.9 \%( \pm 56.6 \% \mathrm{~s})$ and $259.5 \% \mathrm{~s}( \pm 59.2 \% \mathrm{~s})$, respectively. At $2.4 \mathrm{~Hz}, \mathrm{MMV}$ was $180.4 \% \mathrm{~s}( \pm 54.8 \% \mathrm{~s})$ in the iSCI group and $251.7 \% \mathrm{~s}( \pm 76.8 \% \mathrm{~s})$ in the control group. However, the groups did not significantly differ in MVC in dorsiflexion $(\mathrm{p}=0.456)$ (Fig. $2 \mathrm{~B})$. Isometric torque (normalized for body weight) was $0.35 \mathrm{Nm} / \mathrm{kg}$ $( \pm 0.12 \mathrm{Nm} / \mathrm{kg})$ in the iSCI group and $0.38 \mathrm{Nm} / \mathrm{kg}$ $( \pm 0.07 \mathrm{Nm} / \mathrm{kg})$ in the control group. Nevertheless, ankle timing in the supine position as well as the initiation and termination of dorsiflexion in swing were independent of MMV and MVC.

\section{Timing of ankle dorsiflexion versus gait speed}

In the iSCI group, preferred and maximal gait speed were $0.55 \mathrm{~s}^{-1}\left( \pm 0.18 \mathrm{~s}^{-1}\right)$ and $0.77 \mathrm{~s}^{-1}\left( \pm 0.29 \mathrm{~s}^{-1}\right)$, respectively. In the control group, preferred gait speed was $0.88 \mathrm{~s}^{-1}\left( \pm 0.09 \mathrm{~s}^{-1}\right)$, maximal gait speed was $1.39 \mathrm{~s}^{-1}$ $\left( \pm 0.18 \mathrm{~s}^{-1}\right)$. Both, maximal and preferred gait speed significantly differed between the groups $(\mathrm{p}<0.001)$. Neither accuracy in timing in the supine position nor the time of initiation of dorsiflexion in swing correlated with maximal or preferred gait speed. However, within the iSCI group, MMV in dorsiflexion at $2.4 \mathrm{~Hz}$ correlated to gait speed $\left(r_{S}=0.66\right.$ and $p=0.02$ for maximal and preferred gait speed) as did MVC in dorsiflexion $\left(\mathrm{r}_{\mathrm{S}}=0.80\right.$, $p=0.006$ for maximal and $r_{S}=0.83, p=0.003$ for preferred gait speed).

\section{Discussion}

The purpose of this study was to investigate timing of ankle dorsiflexion in iSCI patients and to study the impact of spinal cord damage on this aspect of motor control. Timing of ankle dorsiflexion was compared between iSCI subjects and healthy controls and related to measures for CST conductivity (assessed by MEP), MMV, MVC and gait speed. Although gait speed, MEP parameters and MMV were significantly impaired in the iSCI subjects, there was no difference in timing of ankle dorsiflexion between iSCI patients and controls, neither during gait nor in the supine position. In addition, timing of ankle dorsiflexion was not related to muscle strength and gait speed.

\section{Cortical control of ankle dorsiflexion}

Ankle dorsiflexion was shown to be under large cortical control, both during gait and in the supine position. Enhanced CST activity in the swing phase of gait was reported in animals $[4,11,20,28]$ as well as in man $[31,32]$.


Fig.2 MMV and MVC in dorsiflexion. A Maximal movement velocity (MMV) was significantly reduced in the $\mathrm{iSCl}$ group compared to healthy controls at all frequencies. B Maximal voluntary contraction (MVC), however, did not significantly differ between the groups. The star indicates extreme values that are more than 3 times the interquartile range from the end of the box.

Nevertheless, spinal networks that are involved in the generation of reciprocal rhythmic movement pattern for simple locomotion substantially enhance cortical control of locomotion $[5,15,22]$. In the supine position, a functional magnetic resonance imaging (fMRI) study in stroke patients using a paced dorsiflexion paradigm, 
which was very similar to the task presented in this study, showed strong cortical control of the ankle movement and reported an increase in fMRI activation in parallel to progress in gait speed and lower extremity motor control (Fugl-Meyer assessment [21]) [18]. Therefore, timing of ankle dorsiflexion in the supine position and during gait can be regarded as an aspect of dexterity, which is, apart from muscle strength, a separate aspect of motor control [1].

\section{Dexterity in gait and in the supine position}

Since initiation and termination of dorsiflexion in swing are dependent on gait speed [35], the same walking speed was chosen for both the iSCI patients and the control subjects. Nevertheless, apart from a slight delay, none of these measures was significantly altered in the iSCI group, which indicates that gait cycle control was not considerably impaired. This is in contrast to other groups of patients with CNS lesions, where alterations in the duration of swing were reported $[10,13,23]$. In addition, in the elderly, a delay in ankle dorsiflexion in swing was shown to be predictive of falls [26]. Although over-ground and treadmill walking were shown to be very similar in terms of kinematics and kinetic parameters [30], the sensory input provided by the driven walking belts might help to improve the timing of gait cycle. However, the time of initiation of dorsiflexion significantly correlated to MEP latency, which confirms the findings of a strong supraspinal (cortical) influence on the swing phase during gait $[31,32]$.

In the supine position, dexterity was only slightly reduced in the iSCI patients, but not significantly impaired. Although dexterity tests might be confounded by muscle strength, since a well controlled movement requires a certain amount of strength to be performed [7], the present motor paradigm in the supine position demonstrated that accuracy in timing did not depend on either MMV or on MVC. Thus, the iSCI patients and the controls were comparably able to switch from dorsal- to plantar-flexion and vice versa, although the MMV of the iSCI patients was significantly reduced. Furthermore, dexterity in the supine position did not correlate to the MEP parameters in the present study, despite previous evidence for a cortical involvement in ankle dorsiflexion tasks [18]. This result shows that the ability to generate dynamic muscle strength is more responsive to an impairment of corticospinal pathways than dexterity (at least as dexterity was assessed in the present study). Although the iSCI patients showed considerable recovery of static muscle strength with preserved ankle dexterity, gait speed and dynamic strength were significantly reduced. This indicates that impaired ankle dexterity is not the main factor that leads to impaired limb movements after iSCI.

\section{Maximal movement velocity and maximal voluntary contraction}

The sample in the present study included iSCI patients with good recovery of static strength (no significant difference in MVC compared to controls) and walking capacity. Nevertheless, their MMV remained significantly reduced, which confirms slowing of movement to be a common feature after CNS lesions [6,29]. The dynamic measure MMV strongly correlates to muscle strength [38]. Thus, the interesting result of similar static, but significantly different dynamic muscle strength in the two groups is in line with a recent finding that the rate of torque development was dramatically reduced in iSCI patients, while electrically elicited contractile properties did not differ compared to control subjects [25]. In addition, this finding emphasizes the need for a dynamic assessment tool to detect and follow motor deficits after iSCI [29].

\section{Conclusions}

The separate assessment of dexterity and paresis in the ankle showed that timing of ankle dorsiflexion was significantly less impaired than muscle strength in iSCI patients. This supports the assumption that the loss of strength, particularly of dynamic strength, is a major component leading to motor impairment of the lower limb in iSCI, which might be considered in the assessment of treatment interventions.

Acknowledgements We are much obliged to all patients for their participation in this study. We thank Rachel Jurd for editorial support. This work was funded by the International Spinal Research Trust (ISRT), Clinical Initiative Stage II. 


\section{References}

1. Ada L, O'Dwyer N, Green J, Yeo W, Neilson P (1996) The nature of the loss of strength and dexterity in the upper limb following stroke. Hum Mov Sci 15:671-687

2. American Spinal Injury Association (2002) International Standards for Neurological and Functional Classification of Spinal Cord Injury, Chicago

3. Aschersleben G, Prinz G (1995) Synchronizing actions with events: The role of sensory information. Percept Psychophys 57:305-317

4. Beloozerova, IN, Sirota MG, Swadlow HA (2003) Activity of different classes of neurons of the motor cortex during locomotion. J Neurosci 23:1087-1097

5. Butt S, Kiehn O (2003) Functional identification of interneurons responsible for left-right coordination of hindlimbs in mammals. Neuron 38: 953-963

6. Canning C, Ada L, O’Dwyer N (1999) Slowness to develop force contributes to weakness after stroke. Arch Phys Med Rehabil 80:66-70

7. Canning CG, Ada L, O’Dwyer N (2000) Abnormal muscle activation characteristics associated with loss of dexterity after stroke. J Neurol Sci 176:45-56

8. Canning CG, Ada L, Adams R, O'Dwyer $\mathrm{N}$ (2004) Loss of strength contributes more to physical disability after stroke than loss of dexterity. Clin Rehabil 18:300-308

9. Catz A, Itzkovich $M$, Agranov E, Ring H, Tamir A (2001) The spinal cord independence measure (SCIM): Sensitivity to functional changes in subgroups of spinal cord lesion patients. Spinal Cord 39:97-100

10. Chen G, Patten C, Kothari D, Zajac F (2005) Gait differences between individuals with post-stroke hemiparesis and non-disabled controls at matched speeds. Gait Posture 22:51-56

11. Courtine G, Roy R, Raven J, Hodgson J, Mckay H, Yang H, Zhong H, Tuszynski M, Edgerton (2005) Performance of locomotion and foot grasping following a unilateral thoracic corticospinal tract lesion in monkeys. Brain 128: 2338-2358

12. Curt A, Keck ME, Dietz V (1998) Functional outcome following spinal cord injury: significance of motor-evoked potentials and ASIA scores. Arch Phys Med Rehab 79:81-86

13. Den Otter A, Geurts A, Mulder Th, Duysens J (2006) Gait recovery is not associated with changes in the temporal patterning of muscle activity during treadmill walking in patients with post-stroke hemiparesis. Clin Neurophysiol 117:4-15
14. Diehl P, Kliesch U, Dietz V, Curt A (2006) Impaired facilitation of motor evoked potentials in incomplete spinal cord injury. J Neurol 253:51-57

15. Dietz V (1992) Human neuronal control of automatic functional movements: Interaction between central programs and afferent input. Physiol Rev 72:33-69

16. Ditunno JF, Ditunno PL, Graziani V, Bernardi M, Castellano V, Marchetti M, Barbeau H, Frankel HL, D'Andrea JM, Ko H-Y, Marshall R, Nance P (2000) Walking index for spinal cord injury (WISCI): an international multicenter validity and reliability study. Spinal Cord 38:234-243

17. Ditunno PL and Ditunno JF (2001) Walking index for spinal cord injury (WISCI II): scale revision. Spinal Cord 39:654-656

18. Dobkin B, Firestine A, West M, Saremi K, Woods R (2004) Ankle dorsiflexion as an fMRI paradigm to assay motor control of walking during rehabilitation. Neuroimage 23:370-381

19. Dobkin B, Apple D, Barbeau H, Basso M, Behrmann A, Deforge D, Ditunno J, Dudley G, Elashoff R, Fugate L, Harkema S, Saulino M, Scott M (2006) Weight-supported treadmill vs overground training for walking after acute incomplete SCI. Neurology 66:484-493

20. Drew T, Jiang W, Widajewicz W (2002) Contributions of the motor cortex to the control of the hindlimbs during locomotion in the cat. Brain Res Brain Res Rev 40:178-191

21. Gladstone D, Danells C, Black S (2002) The Fugl-Meyer Assessment of motor recovery after stroke: a critical review of its measurement properties. Neurorehabil Neural Repair 16:232-240

22. Grillner S, Ekeberg O, El Manira A, Lansner A, Parker D, Tegner J, Wallen P (1998) Intrinsic function of a neuronal network - a vertebrate central pattern generator. Brain Res Rev 26:184-197

23. Gutierrez G, Chow J, Tillman M, McCoy S, Castellano V, White L (2005) Resistance training improves gait kinematics in persons with multiple sclerosis. Arch Phys Med Rehabil 86:1824-1829

24. Hsu A, Tang P, Jan M (2002) Test-retest reliability of isokinetic muscle strength of the lower extremities in patients with stroke. Arch Phys Med Rehabil 83:1130-1137

25. Jayaraman A, Gregory CM, Bowden M, Stevens JE, Shah P, Behrmann AL, Vandenborne K (2006) Lower extremity skeletal muscle function in persons with incomplete spinal cord injury. Spinal Cord 44:680-687
26. Kemoun G, Thoumie P, Boisson D, Guieu D (2002) Ankle dorsiflexion delay can predict falls in the elderly. J Rehabil Med 34:278-283

27. Krawetz P, Nance P (1996) Gait analysis of spinal cord injured subjects: effects of injury level and spasticity. Arch Phys Med Rehabil 77:635-638

28. Lavoie S, Drew T (2002) Discharge characteristics of neurons in the red nucleus during voluntary gait modifications: a comparison with the motor cortex. J Neurophysiol 88:1791-1814

29. Miller T, Claiborne Johnston S (2005) Should the Babinski sign be part of the routine neurologic examination? Neurology 65:1165-1168

30. Riley PO, Paolini G, Croce UD, Paylo KW, Kerrigan DC (2007) A kinematic and kinetic comparison of overground and treadmill walking in healthy subjects. Gait Posture 26:17-24

31. Schubert M, Curt A, Jensen L, Dietz V (1997) Corticospinal input in human gait: modulation of magnetically evoked motor responses. Exp Brain Res 115:234-246

32. Schubert M, Curt A, Colombo G, Berger W, Dietz V (1999) Voluntary control of human gait: conditioning of magnetically evoked motor responses in a precision stepping task. Exp Brain Res 126:583-588

33. Van Hedel H, Wirz M, Dietz V (2005) Assessing walking ability in subjects with spinal cord injury: validity and reliability of 3 walking tests. Arch Phys Med Rehabil 86:190-196

34. Van Hedel H, Wirz M, Curt A (2006) Improving walking assessment in subjects with a spinal cord injury: responsiveness. Spinal Cord 44:352-356

35. Van Hedel HJ, Tomatis L, Müller R (2006) Modulation of leg muscle activity and gait kinematics by walking speed and bodyweight unloading. Gait and Posture 24:35-45

36. Van Hedel H, Murer C, Dietz V, Curt A (2007) The amplitude of lower leg motor evoked potentials is a reliable measure when controlled for torque and motor task. J Neurol 254: 1089-1098

37. Waters RL, Adkins RH, Yakura JS, Sie I (1994) Motor and sensory recovery following incomplete paraplegia. Arch Phys Med Rehabil 75:67-72

38. Wirth B, van Hedel H, Curt A (2007) Foot control in incomplete SCI: distinction between paresis and dexterity. Still in press 